\title{
Fernando de Antequera y el Compromiso de Caspe. ¿Una incorporación a España? *
}

\author{
JOSÉ-LUIS MARTÍN **
}

\begin{abstract}
RESUMEN
ABSTRACT

Utilizando los mismos documentos,

Using the same documents, castilians

historiadores castellanistas y and catalonians historians have given

catalanistas han ofrecido visiones

completamente opuestas sobre el completely different approaches about the Agreement of Caspe, by which the Compromiso de Caspe, en el que fue elegido el castellano Fernando de Antequera rey de Aragón. Unos y otros se sitúan en el siglo $x x$ y trasladan a 1412 sus opiniones sobre las ventajas

e inconvenientes de la unidad de

España y, según sea su planteamiento, ofrecen una versión negativa de Caspe, quienes creen que

Cataluña debe recuperar la independencia de tiempos medievales, o dan una versión altamente positiva, convencidos de que Caspe propició la formación de España, la unión de las Coronas de Castilla y de Aragón. castilian Fernando de Antequera was elected King of Aragón. Both groups of historians belong to the $20^{\text {th }}$ century and transfer to the year 1412 their view about the advantages and inconvenients of the Spanish Unity. Depending on their opinion, there is a negative version of that agreement by those who believe that Catalonia should recover the independence of the middle - ages time. Others give a highly positive version as they are convinced that Caspe favoured the birth of Spain with the joint of the Crowns of Castile and Aragón.
\end{abstract}

\footnotetext{
* El punto de partida del texto es una conferencia pronunciada, hace algún tiempo, en Barcelona.

** UNED.
} 
Hablar en Barcelona del Compromiso de Caspe en un ciclo titulado Catalunya dins d'Espanya? es, cuando menos, valga la redundancia, un compromiso, especialmente si la conferencia lleva el subtítulo Una incorporació a Espanya?. Con el riesgo evidente de equivocarme, pienso que al lector y al oyente interesan más las consecuencias que el Compromiso en sí; interesa saber cómo Fernando de Antequera llegó a ser rey de Aragón - más que nada, cómo llegó a ser conde de Barcelona- e importa sobre todo conocer las repercusiones que la elección de un castellano tuvo para la historia posterior, para la historia actual sería más exacto, de Cataluña.

El interés o el valor del texto dependerá de los mayores o menores conocimientos de quien expone y, sobre todo, del mayor o menor soporte que sus argumentos ofrezcan a oyentes que creen tener, y sin duda tienen, una idea clara de lo que significó Caspe para los catalanes y para los demás españoles. Quienes piensen, con Menéndez Pidal, que la unidad de España es deseable o necesaria verán en Caspe un paso más, favorable por tanto, hacia esa unidad, diga lo que diga quien habla o escribe; y quienes opinan con Ferran Soldevila - por citar sólo a los historiadores más representativos de las contrapuestas teorías sobre Caspe-que Cataluña debió y debe mantener su independencia, rechazarán cualquier argumento que justifique la decisión tomada en Caspe. El compromiso es mayor cuando quien habla está convencido de que ni Menéndez Pidal ni Soldevila trataron el tema con la objetividad del historiador sino con la subjetividad del "partidario de" y del "contrario a» la unidad de España. En este sentido, tienen validez, aplicadas a ambos historiadores, las palabras de Soldevila: «Este trascendental acontecimiento es uno de aquéllos cuyo verdadero carácter, aunque se aclare con luz meridiana y con pruebas incontrovertibles, jamás llegará a conocerse totalmente, porque nunca faltará quien surja desplegando cortinas de humo que enturbien su claridad y tergiversen las pruebas para convertirlas en ineficaces y contrapuestas" '.

A pesar de que muchos tengan formada una opinión me permitirán que explique en pocas palabras lo ocurrido entre la muerte de Martín el Humano y la elección del Trastámara castellano como rey de Aragón y

\footnotetext{
Las palabras de Soldevila - la traducción es mía- pueden verse en El Compromís de Casp (Resposta al Sr. Menéndez Pidal), Barcelona 1965. La obra de Menéndez Pidal a la que se refiere Soldevila es la introducción al tomo XV de la Historia de España, dirigida por don Ramón Menéndez Pidal, Madrid 1964, pp. IX-CLXIV; su título es «El Compromiso de Caspe, autodeterminación de un pueblo». El lector encontrará en estas obras cuantos datos pueda desear sobre el Compromiso.
} 
conde de Barcelona para, en la segunda parte, referirme a las consecuencias de Caspe, a resolver el interrogante planteado en el subtítulo de esta conferencia.

\section{CANDIDATOS A LA SUCESIÓN}

De nada sirve lamentar la muerte de Martín el Joven en 1409 y son inútiles las elucubraciones sobre lo que habría podido ocurrir si el heredero hubiera sobrevivido a su padre o si éste hubiese logrado descendencia de su tardío y apresurado matrimonio con Margarita de Prades ${ }^{2}$; el 31 de mayo de 1410 moría Martín el Humano sin herederos directos legítimos y sin haber indicado de una forma clara quién habría de sucederle; sus consultas sobre si el sucesor podía ser designado libremente por el monarca entre los miembros de la familia real, y en caso afirmativo, si podía designar a su nieto Fadrique, no obtuvieron respuesta, y tampoco se aclaró si el parentesco se limitaba a Martín el Humano o debía remontarse a sus antecesores; no hubo respuesta quizá porque no había una respuesta única o tal vez porque la solución legal, fuera cual fuese el resultado, implicaba efectos de todo tipo que los estamentos de los reinos y del Principado no estaban dispuestos a aceptar.

El silencio de los juristas contemporáneos no ha impedido que los historiadores hayan vertido ríos de tinta para contestar, casi siempre interesadamente, a las preguntas del rey Martín. Federico o Fadrique de Luna, hijo ilegítimo de Martín el Joven, ha sido eliminado por su origen que, según el Derecho, lo incapacitaba para reinar. La afirmación es cierta y si hubiera dudas bastaría recordar las palabras de Eiximenis: los bordes son «inaptes a actes legítims eclesiàstics e seglars" ${ }^{3}$ por no recordar la comparación que establece, siguiendo el dicho popular, entre

\footnotetext{
2 Entre las numerosas «novias» buscadas al rey aragonés hay que incluir a Beatriz de Portugal, protegida del candidato Fernando de Antequera, según el relato del alférez de Pero Niño, conde de Buelna: «E a la otra su hija (Beatriz, hija del infante Juan de Portugal) tomóla el ynfante don Fernando... e desposóla con el ynfante don Enrrique, su hijo... En este tiempo el rey don Martín de Aragón, o sabía o non savía cómo doña Beatriz fuese desposada con el ynfante don Enrrique; envióla demandar al ynfante don Hernando, para casar con ella. El ynfante hera muy amado del rey don Martín, e esperava que le fiçiese heredero del reyno de Aragón. El ynfante otorgógelo; e durante los tratos del casamiento, casó el rey con una donzella de su casa que llamavan doña Margarita de Pensas..." El Victorial, crónica de don Pero Niño, conde de Buelna, por su alférez GutierRe Díez de Games. Edición y estudio por Juan de Mata Carriazo, Madrid 1940, p. 300).

3 Regiment de la cosa pública, Barcelona 1927. El capítulo XXV está dedicado a explicar Com los borts són comunament mals, e molt a tart n'hi ha que bons sien (pp. 142-144).
} 
el borde y la mula: «Bort e mula, tot jorn ne fan una», pero la ilegitimidad es fácilmente salvable de hecho y de derecho: Roma nunca fue sorda a las peticiones de los reyes amigos cuando éstos quisieron legitimar a sus descendientes, y la sociedad medieval acepta a los ilegítimos incluso en altos cargos eclesiásticos o en el trono, como prueban Enrique II de Trastámara, rey de Castilla al que alude Eiximenis como ejemplo de borde "famós e de gran cavalleria", o Juan de Avis, rey de Portugal, contemporáneo de Martín el Humano. De hecho, se atribuyen al rey aragonés diversos intentos de legitimar a su nieto: consiguió que fuera legitimado para suceder a su padre en el condado de Luna y en el señorío de Segorbe, y al parecer Benedicto XIII pensaba legitimar a Fadrique el 1 de junio y prepararlo asi para la sucesión en el trono. Si fuera preciso buscar ejemplos de aceptación de los ilegítimos podría recurrirse al documento de concubinato suscrito por Jaime I y Aurembiaix de Urgel en el que se prevé la posibilidad de que nazca de esta unión un hijo que heredaría el condado urgelitano ${ }^{4}$. Aunque ilegítimo, Fadrique podría haber sido rey, pero a la muerte de Martín tenía ocho años y carecía de partidarios que apoyaran su candidatura, y el Derecho sin apoyos, poca fuerza tiene.

Menos dudas hay sobre los derechos de Luis de Anjou y de Juan II de Castilla aunque no falten quienes les "reprochen" descender de los reyes de Aragón por vía femenina. Los «legalistas» se dividen entre quienes piensan o imaginan la existencia de una especie de ley sálica vigente en Cataluña y quienes recuerdan que según el Derecho aragonés las mujeres no reinan pero si trasmiten sus derechos a los hijos varones. Los primeros olvidan que los catalanes aceptaron a Costanza, hija de Pedro el Ceremonioso, como heredera del trono en 1347 y los segundos prefieren ignorar que uno de los argumentos de los unionistas aragoneses para oponerse a Fedro el Ceremonioso fue precisamente el nombramiento de Costanza. La vigencia o el rechazo de la ley sálica está en función de los intereses de cada momento: en 1377 Federico el Simple de Sicilia dejó como heredera a su hija María, y Pedro el Ceremonioso recusó esta designación basándose en la vigencia de la ley sálica en Sicilia y reclamó el trono para sí como heredero de su hija Costanza, mujer de Federico. Al no ver reconocidos sus derechos intentó recuperar Sicilia mediante el matrimonio de su hijo Juan con la heredera, lo que equivalia de hecho a negar vigencia a la ley sálica. Finalmente, Sicilia

4 El texto ha sido publicado por Ferrán SOLDEVILA, Els primers temps de Jaume I, Barcelona 1968, pp. 299-300. 
volvió a la Corona gracias al matrimonio de Martín el Joven con la princesa siciliana ${ }^{5}$.

Otra prueba del escaso valor real de la ley sálica la hallamos en los intentos de Mateo de Foix de alcanzar el trono a la muerte de Juan I, alegando los derechos de su esposa Juana, hija de Juan; sus pretensiones estaban legitimadas por los capítulos matrimoniales concertados entre Juan I y su segunda esposa Matha de Armagnac según los cuales si el rey no tuviera hijos varones de este matrimonio el reino pasaría a su hija mayor, habida en el primer matrimonio ${ }^{6}$. Si fueran necesarias más pruebas bastaría recordar que durante la guerra civil de la segunda mitad del siglo xv los catalanes eligieron como reyes, sucesivamente, a Enrique IV de Castilla, a Pedro de Portugal y a Renato de Anjou descendientes de los reyes de Aragón por línea femenina.

Nada sabemos sobre si el parentesco habría de referirse a Martín o a sus antecesores, y según la respuesta que se dé, varía el orden de los candidatos: si la referencia es Martín el Humano tienen mayores derechos Luis de Anjou y Juan II de Castilla, sobrinos segundos de Martín; y si el parentesco se establece con otros monarcas, Fernando de Antequera es nieto de Pedro el Ceremonioso, Alfonso de Gandía es nieto de Jaime II y Jaime de Urgel bisnieto de Alfonso el Benigno. Justo es reconocer que Alfonso de Gandía murió el 5 de marzo de 1412, antes de que se reunieran en Caspe los compromisarios y que sus derechos pasaron a su hijo cuyo parentesco con los reyes era el de bisnieto, es decir el mismo que el de Jaime de Urgel.

A resolver o a complicar la discusión sobre los derechos de los ilegítimos o de los descendientes por línea femenina así como sobre a quién ha de referirse el grado de parentesco puede contribuir el testamento redactado por Jaime I el 26 de agosto de 1272. En esta fecha, el monarca dividió sus dominios entre sus hijos Pedro y Jaime y fijó la línea de sucesión para siempre: «Queremos, establecemos y mandamos que si ocurriera, Dios no lo permita, que dicho infante Pedro, hijo nuestro primogénito, o sus hijos varones legítimos o sus descendientes en línea recta, varones y legítimos, murieran $\sin$ hijo o sin hijos legítimos y varones, los reinos y

\footnotetext{
5 Pueden verse estos aspectos en cualquiera de las múltiples Historias de Cataluña existentes, por ejemplo en la coordinada por A. BALCELLS y escrita en su parte medieval por J. M. SalRACH, Història dels països catalans, vol. 2, Dels orígens a 1714, Barcelona 1981, pp. 736-742 y $763-764$.

6 Ob. cit., en la nota antrerior, p. 781.
} 
condados junto con todas las otras cosas que le dejamos sean devueltas al infante Jaime, hijo nuestro, heredero de Mallorca, o a sus hijos o descendientes en línea recta, legítimos y varones, al que fuera rey de Mallorca y señor de Montpellier». Idénticas normas fija el rey para el caso de que fuera Jaime de Mallorca o sus descendientes los que murieran sin hijos. Las previsiones del rey van más allá, incluyen la posibilidad de que ambos infantes mueran sin hijos varones legítimos en cuyo caso el heredero será Jaime, hijo habido en la unión, no legalizada, del Conquistador con Teresa Gil de Vidaurre, y si tampoco Jaime tuviera descendencia masculina, heredaría el trono su hermano Pedro. Finalmente, agotadas todas las posibilidades de descendencia por línea masculina, legítima o ilegítima, el monarca recurre a sus hijas como transmisoras del derecho al trono a sus hijos varones. "los reinos y condados antedichos y la villa de Montpellier con su dominio y todas las cosas citadas anteriormente, sean entregadas a los hijos varones y legítimos de la ilustre reina de Castilla doña Violante, hija nuestra; y si no tuviera hijos legítimos varones, todas las cosas citadas pasen a los hijos varones y legítimos de doña Costanza nuestra hija..., y faltando hijos varones legítimos de dicha Costanza, todo lo anterior sea concedido a los hijos varones legítimos de doña Isabel hija nuestra y reina de Francia en otro tiempo; y faltando todos los citados... queremos y mandamos que todo sea entregado a aquel que sea el más próximo a nosotros en línea de parentela, siempre que sea varón y legitimo y descienda en línea recta de nuestra estirpe» ?.

El testamento establece una línea clara de sucesión aunque, como veremos, no resuelve el problema: el trono corresponderá primero a los hijos legítimos, en segundo lugar a los ilegítimos y, en último término, a los descendientes por vía femenina. La dificultad estriba en saber si un testamento sienta jurisprudencia y, aceptada ésta, si el centro a partir del cual se fija la línea de sucesión ha de ser inevitablemente Jaime I o puede ser cualquiera de sus sucesores. Si el punto de referencia es Martín, el heredero sería Fadrique y sólo tras su muerte sin hijos varones y legítimos el reino pasaría a otro de los candidatos; si se parte de Pedro el Ceremonioso, serían herederos tras la muerte de Juan I y de Martín sin descendientes varones, los hijos de Leonor, es decir Enrique III de Castilla - Juan II tras su fallecimiento- $y$ su hermano Fernando de Antequera, y tomando al pie de la letra el testamento de Jaime I habría que aplicar la última cláusula que favorece a Jaime de Urgel y Alfonso de Gandía.

7 Estudié el testamento en «Los reinos hispánicos a fines de la Edad Media», Anuario de estudios medievales, 3, 1966, pp. 685-686. 
Nada clara la vía legal, Martín pudo haber designado sucesor de hecho $y$ en este sentido cabe interpretar el nombramiento de Jaime de Urgel como Lugarteniente en el Reino de Aragón (15 de junio de 1408) y sobre todo su designación, una vez muerto Martín el Joven, como Gobernador General de todos los reinos (25 de agosto de 1409). Sus derechos legales unidos a la fuerza proporcionada por el cargo lo habrían convertido automáticamente en rey si aragoneses, catalanes y valencianos no hubieran estado enfrentados entre si: bastará que uno de los bandos apoye a Jaime de Urgel, el candidato mejor situado por residir en tierras de la Corona, por su edad (treinta años frente a los 8 de Fadrique o los 6 de Luis de Anjou) y por estar casado con Isabel, hermanastra de Martín, para que el bando contrario busque apoyo en otro de los candidatos, que inicialmente será Luis de Anjou que cuenta con el apoyo de los antiguos consejeros de Juan I, influyentes a pesar del juicio promovido contra ellos durante el reinado de Martín ${ }^{8}$.

\section{Jaime de Urgel y Fernando de Antequera}

Aun cuando los cronistas castellanos hablen de los derechos de Fernando de Antequera y de la predilección que hacia él sentía Martín el Humano, Fernando es el último de los candidatos en hacer valer sus derechos y en los primeros momentos sólo hay dos aspirantes serios, dos candidatos que tengan partidarios decididos a imponerlos: Jaime de Urgel y Luis de Anjou. Sabemos por la Crónica de Juan II de Castilla que al morir Martín el Joven el infante castellano envió una embajada al monarca aragonés para condolerse de la muerte del hijo y, de paso, recordarle “cómo el reyno de Cecilia le pertenescía de derecho" " ${ }^{\text {; los embajadores }}$ permanecieron en Aragón y «trabajaron quanto pudieron -especialmente después de la muerte del rey- por saber quál destos (de los candidatos) tenía mayor derecho al Reyno o si pertenecía al Infante Don Fernando por ser pariente más propinco del Rey Don Martín de Aragón que ninguno de los que lo demandaban», pero ocupado en el sitio de Antequera y creyendo sin duda que sus posibilidades eran escasas Fernando "dexó de entender en las cosas de Aragón».

8 V. la obra de Martín de Riquer, Obres de Bernat Metge, Barcelona 1959, y el artículo de Marina MITJÀ, «Procés contra els consellers, domèstics i curials de Joan l, entre ells Bernat Metge», Boletín de la Real Academia de Buenas Letras de Barcelona, XXVI1, 1957-58, pp. 375-417.

9 Crónicas de los Reyes de Castilla, II, Madrid 1953. Interesan para el conocimiento del Compromiso las pp. 327, 333, 336 y ss. 
Sorprende este aparente desinterés en un candidato que está convencido de sus derechos y que nada más tomar Antequera reúne a los arzobispos del reino y a los letrados laicos y eclesiásticos y organiza una disputa en la que "los unos tomaron la parte del infante e los otros la de los que demandaban el Reyno" para concluir finalmente que el reino aragonés pertenecía al Infante. Las causas del retraso son de tipo práctico y de naturaleza legal: sus derechos chocan con los de su sobrino Juan II de Castilla (los letrados de la Corte y de la Chancillería "hallaron que el Rey Don Juan de Castilla y el Infante Don Fernando, su tío... tenían derecho al Reyno...") y Fernando no dispone de medios para hacer valer sus derechos si finalmente son reconocidos. El dinero será facilitado por las Cortes, reunidas en 1410 para dar al regente castellano los medios para reemprender la guerra contra los musulmanes una vez que expire la tregua (el 10 de abril de 1412). De la renuncia de Juan II y de conseguir que el dinero de la guerra se destine a la campaña aragonesa se encargará más tarde Fernando con la ayuda de la reina madre, Catalina de Lancaster, que deseaba alejar de Castilla a su cuñado Fernando y esperaba, según Torres Fontes, que renunciara a la regencia de Castilla ${ }^{10}$.

De nada habrían servido los derechos del Infante si aragoneses, catalanes y valencianos hubieran actuado de acuerdo o si cualquiera de los reinos o el Principado hubiera tenido fuerza para imponer su punto de vista a los demás; la división interna y el control del Infante sobre Castilla hicieron posible su acceso al trono aragonés; mientras el castellano controla las Cortes y consigue de éstas dinero y hombres para defender su candidatura, aragoneses, valencianos y catalanes, cada uno por su lado, se enfrentan en una guerra civil en la que cada bando defiende sus intereses so pretexto de hacer valer los derechos de Jaime de Urgel o de Luis de Anjou; cada grupo aspira a colocar en el trono a quien le sea favorable y persiga a sus enemigos, y mientras no conozcamos las causas de estos enfrentamientos seguiremos ignorando por qué no fue nombrado el rey inmediatamente después de la muerte de Martín. El retraso perjudicó a Jaime de Urgel y favoreció al pretendiente castellano, inactivo como tal hasta finales de septiembre, que tuvo su oportunidad cuando uno de los máximos defensores de Luis de Anjou,el arzobispo de Zaragoza García Fernández de Heredia, fue asesinado (1 de junio de 1411) por Antón de Luna, partidario de Jaime de Urgel. Los amigos del asesinado necesitaban ayuda urgente y sólo Fernando, próximo a la frontera, estaba en condiciones de dársela: los angevinos aragoneses no dudaron en declararse fervientes partidarios

10 "La regencia de don Fernando de Antequera», Anuario de Estudios Medievales, 1 (1964), pp. 3675-419. 
del Trastámara castellano que unía así derechos, partidarios en el reino y medios económicos y militares para hacer efectivos los primeros con la ayuda de los segundos que se muestran decididos a actuar inmediatamente, incluso solos si catalanes y valencianos no se ponen de acuerdo.

Las Cortes catalanas se trasladan de Barcelona a Tortosa en búsqueda de la cercanía con los parlamentos de Aragón y de Valencia, pero mientras los catalanes se eternizan en discusiones que a nada conducen y los valencianos se hallan divididos en tres parlamentos irreconciliables, los aragoneses, bajo la protección de las armas castellanas, se reúnen en Alcañiz no sin recordar a los que no asistan que, en su ausencia, se procederá sin ellos; de esta manera se eliminaba a los seguidores de Jaime de Urgel, es decir a Antón de Luna y a sus amigos, excomulgados por el asesinato del arzobispo zaragozano y, por tanto, incapacitados para ejercer cualquier derecho, para asistir a la reunión. Los protegidos por Fernando de Antequera actúan, pues, como representantes únicos de Aragón y a ellos se opondrán los urgelistas que reúnen su propio parlamento en Mequinenza.

Unos y otros buscarán ser reconocidos por los catalanes reunidos en Tortosa adonde acuden igualmente los valencianos, también divididos entre sí e integrados en dos e incluso tres parlamentos por razones internas que no tardan en trasformarse en dinásticas: si el Gobernador Arnau Guillem Bellera y Juan de Vilaragut se declaran urgelistas, sus enemigos, los Centelles, aceptarán la ayuda de tropas aragonesas y castellanas para combatir a sus enemigos y no tardarán en aceptar la candidatura de Fernando de Antequera.

El papel de árbitro entre aragoneses y valencianos interpretado por Tortosa habría permitido a los catalanes decidir por sí solos a fines de 1411, pero la decisión no se produjo y las discusiones se prolongaron durante meses que fueron aprovechados por los candidatos para fortalecer sus posiciones y acusarse mutuamente de sobornos, de utilización en beneficio propio del cargo de Gobernador General, de introducir tropas extrañas en el reino o de buscar una alianza con los musulmanes de Granada para crear problemas en Castilla a Fernando de Antequera.

Fueran ciertas o falsas las acusaciones y las justificaciones que ofrecen los candidatos - la aceptación o el rechazo dependen hasta ahora del candidato por el que se apueste-, es indudable que a comienzos de 1412, año y medio después de la muerte de Martín, todos estaban convencidos de que era imposible reunir a aragoneses, valencianos y catalanes y comienza a abrirse paso la idea, interesada, de que si por separado han sido incapaces de llegar a un acuerdo, la reunión conjunta de poco serviría. En este contexto se presenta la propuesta de Alcañiz: los parlamentos, aparte de 
ineficaces, no deben decidir a quién corresponde en justicia el reino sino tan sólo elegir «personas de santa vida y ciencia, buenas y notables» a las que se encomendará la decisión final; una carta del papa Benedicto XIII (del 23 de enero de 1412) refuerza la propuesta de Alcañiz, que sería aceptada por los representantes de Tortosa el 15 de febrero de 1412. La designación del nuevo rey será encomendada a una comisión de nueve personas, tres de cada grado que decidirán «según Dios y en conciencia».

El plazo para nombrarlas es de veinte días, y los elegidos se reunirán en Caspe el 29 de marzo. Para que su decisión sea válida se exige que, como mínimo, la apoyen seis compromisarios y que, al menos, haya uno de cada grado, sin especificar si el grado se refiere a los estamentos (eclesiásticos, nobles y ciudadanos) o a los reinos de Aragón y Valencia y al Principado de Cataluña. Los valencianos serán aceptados si previamente se ponen de acuerdo, y tanto Jaime como Fernando intentarán, en el breve plazo de que disponen, conseguir que los valencianos estén representados por sus partidarios; de esta forma se explica el rebrote de la violencia entre Vilaraguts y Centelles y el apoyo que a unos y otros prestan, respectivamente, Jaime de Urgel y Fernando de Antequera. Las tropas castellanas obtienen la victoria de Murviedro - 27 de febrero- que permite a los valencianos antequeristas adherirse a la Concordia de Alcañiz.

La designación de los neuve jueces no es fácil; los aragoneses confían su nombramiento al Gobernador y al Justicia del Reino, tan de acuerdo que el 2 de marzo, tres días antes de que finalice el plazo, tienen preparada la lista. Los compromisarios serían los valencianos Bonifacio Ferrer, Gener Rabaça y Vicente Ferrer, con claro predominio de hombres de Benedicto XIII, interesado en la sucesión puesto que de ella depende su permanencia en el pontificado ${ }^{11}$. El arzobispo de Tarragona, el jurista Guillem de Vallseca y el síndico barcelonés Bernat de Gualbes representarían a Cataluña, y el obispo de Huesca, el jurista Berenguer de Bardaji y Francisco de Aranda - hombre del Pontífice- llevarían la voz aragonesa. La propuesta, hecha por los aragoneses protegidos del pretendiente castellano, sólo sería viable si era aprobada por los representantes de las Cortes catalanas que, sin lista propia, terminaron aceptando como base de discusión y aprobando finalmente, el 14 de marzo, la lista aragonesa. Todos fueron aceptados por unanimidad, excepto Gualbes, que obtuvo dieciséis votos sobre un total de veintitrés, y Bonifacio Ferrer que consiguió dieciocho votos.

1t Si Castilla y Aragón, unidos, apoyan al Papa Luna sus posibilidades de mantenerse en el Pontificado son mucho mayores que si uno de los reinos decide inclinarse hacia el Papa de Roma. 
El 24 de junio, tras haber oído a los representantes de los candidatos, los tres aragoneses, Bonifacio y Vicente Ferrer y Bernat de Gualbes dieron su voto a Fernando de Antequera, es decir reconocieron la capacidad de las mujeres pata trasmitir derechos a los hijos varones y eligieron al pariente más próximo de uno de los reyes, Pedro el Ceremonioso, dando así respuesta a la pregunta hecha tres años antes por Martín el Humano. El arzobispo de Tarragona y Guillem de Vallseca se inclinaron hacia la sucesión por línea masculina y consideraron con mayores derechos al duque de Gandía y al conde de Urgel, no sin que el eclesiástico dejara a salvo los posibles derechos de Fadrique de Luna. El tercer valenciano, Pedro Bertrán, llamado para sustituir a Gener Rabaça, se abstuvo alegando no haber tenido tiempo para formar una opinión.

\section{LA SUSTITUCIÓN DE RABAÇA}

El cambio de Rabaça por Bertrán puede dar y ha dado ocasión a numerosas sospechas aunque no se ha insistido porque, visto el resultado, poco importaba su presencia: el hecho de que su candidatura fuera presentada por el parlarnento valenciano de Vinaroz y aceptada sólo en última instancia por los aragoneses aconseja revisar el proceso en el que se le declaró loco e inhábil, por tanto, para formar parte de los nueve. La decisión fue tomada por los ocho compromisarios restantes a petición de un yerno de Gener Rabaça.

Gener es el último de los compromisarios en llegar a Caspe, donde, requerido para prestar juramento el 17 de abril, alega hallarse fatigado por el viaje y pide que se aplace la ceremonia. Dos días más tarde, Francesc Perelló, yerno de Rabaça, solicita que éste sea relevado de sus obligaciones por no ser «bueno ni provechoso para dichos negocios", como podría demostrar si se abriera una investigación. Aunque el texto no alude hasta ahora a la locura de Gener Rabaça, los compromisarios mandaron redactar un cuestionario que debería ser presentado a diferentes testigos y cuya finalidad era averiguar la «demencia o indisposición de la persona de dicho Gener Rabaça». Reproducimos las preguntas por si entre los lectores hay algún especialista que pueda juzgar si el interrogatorio y el modo en que fue realizado eran los más aptos para diagnosticar la locura de Gener Rabaça. Las preguntas fueron:

1. Si conocen al muy honorable y honrado varón Gener Rabaça, caballero y doctor de la ciudad de Valencia. 
2. Si saben o han oído decir o conocen de otro modo por su aspecto o verosímilmente suponen que dicho honorable Gener Rabaça es octogenario, o qué edad tiene.

3. Como sucede algunas veces que los ancianos tengan una mente pueril, si saben o han oído decir o de otro modo suponen verosímilmente a dicho Gener, anciano de dicha edad, trastornado y alienado.

4. Como de las palabras y hechos pueda suponerse a alguien cuerdo o demente, si dicho honorable Gener dice palabras justas y sabias o si profiere frases que suponen enajenación, y cuáles son éstas.

5. Como algunos a veces tienen palabras de sabios y, en cambio, actúan como dementes en la administración de los bienes, si dicho Gener en los asuntos que dirige o administra de sus bienes o de los ajenos actúa como sabio o como mentecato.

6. Si de todo lo anterior y de cada una de las cosas antedichas, creen, piensan o verosímilmente suponen que dicho honorable Gener está cuerdo o demente.

7. Si es fama que dicho honorable Gener, a causa de la edad o por cualquier otra razón, es mentecato, y en qué lugar o entre quiénes existe dicha fama y desde qué tiempo.

8. Teniendo en cuenta que dicho honorable Gener es uno de los nueve elegidos para declarar el derecho a la sucesión del reino de Aragón por justicia, si creen que será hábil, idóneo y suficiente para declararlo junto con los otros.

Los testigos interrogados fueron en total veintidós, de los cuales sólo ocho conocían a Rabaça antes de que éste llegara a Caspe; los testimonios de mayor peso fueron los de Francesc Perelló y Pere Batlle, yerno y escudero, respectivamente, de Gener, y junto con ellos declara el dueño de la casa en la que se alberga el jurista valenciano, cuatro vecinos de Valencia, embajadores del duque de Gandía, uno de los aspirantes al trono, cinco catalanes, cinco aragoneses, tres autoridades de Caspe y dos castellanos, partidarios sin duda de Fernando de Antequera. Al menos en apariencia los testigos son elegidos de modo imparcial y entre ellos se encuentran los que conocen íntimamente a Gener, representantes oficiosos de los Reinos y del Principado y autoridades de Caspe más dos partidarios del aspirante castellano. Además de requerir los testimonios citados, los compromisarios visitaron personalmente a Gener y fueron testigos de algunas extravagancias que confirmaron la sospecha de que el compromisario valenciano no se hallaba en su sano juicio. 
Las respuestas de los testigos fueron imprecisas en muchos puntos, como era lógico en personas que sólo de oídas conocían a Rabaça, pero todos coincidieron en que no era apto para intervenir en la elección, y en algún caso añadieron que tampoco estaba en condiciones de intervenir en cualquier otro asunto, por pequeño que fuese. Ante la coincidencia de opiniones, los ocho compromisarios restantes declararon a Gener Rabaça no «idóneo o suficiente sino, por el contrario, impedido e inhábil para hacer y llevar a cabo lo que les había sido encomendado" ${ }^{12}$ por lo que nombraron para sustituirle al también valenciano Pere Bertrán que, como hemos dicho, no tomó parte en la votación.

Tal como se desarrollaron los hechos, el voto de Gener Rabaça, fuese el que fuese, no habría influido en el resultado de la elección, pero siempre queda la duda de si su intervención en las deliberaciones habría inclinado a alguno de los compromisarios a negar su voto a Fernando de Antequera, que tuvo exactamente los votos que necesitaba. También esta última suposición es inútil: desde el momento en que las tropas castellanas controlaban Aragón y Valencia, el único rey posible, el «más útil» al decir de sus votantes era el pretendiente castellano; cualquier otra solución equivalía a la guerra civil o a la ruptura de la unidad de los territorios de la Corona de Aragón.

\section{¿INCORPORACIÓN A ESPAÑA?}

Podríamos resumir lo dicho hasta ahora recordando que a la muerte de Martín el Humano, Fernando era uno más, y de los menos cualificados, aspirantes al trono, y al reunirse los compromisarios en Caspe se había convertido en el único rey posible. El paso de una situación a otra en el plazo de dos años se vio facilitado por un cúmulo de circunstancias que podemos resumir asi:

1. Falta de fuerza militar de los aragoneses partidarios de Luis de Anjou, que no dudan en seguir a Fernando si éste los apoya contra los seguidores del conde de Urgel. Las posibilidades de Fernando, nulas sin contar con partidarios dentro de la Corona, comienzan a existir al cambiar los angevinos aragoneses el apoyo a Luis por la protección que podía brindarles el pretendiente castellano.

12. Puede verse el interrogatorio en mi artículo "Diagnóstico de una locura en el siglo Xv", Jano, marzo de 1973, reeditado en Economia y sociedad en los reinos hispánicos de la Baja Edad Media, Barcelona 1983, II, pp. 367-375. 
2. La intervención militar castellana refuerza las aspiraciones de Fernando y es posible: a) por las riquezas y el poder acumulados por el regente castellano; b) por el interés de la nobleza castellana en alejar del reino al demasiado autoritario regente, y c) porque interesa al Pontificado, a Benedicto XIII, el triunfo de Fernando para reforzar su vacilante situación.

3. Dominado militarmente el reino de Aragón y poco más tarde el de Valencia, Fernando impone una solución aparentemente legal, utilizando para ello al parlamento aragonés formado por sólo sus partidarios. La actuación del aspirante castellano encontró grandes facilidades por la división existente en el parlamento catalán en el que no habia predominio claro ni de urgelistas ni de angevinos. La aceptación por los catalanes de los compromisarios propuestos por los aragoneses equivalía de hecho a la elección de Fernando, y la reunión de Caspe no hizo sino confirmar la elección previa.

Esta rápida visión puede extraerse de cualquiera de las innumerables obras dedicadas al Compromiso siempre que el lector se limite a los hechos y prescinda de las interpretaciones interesadas y anacrónicas, siempre que no se interprete Caspe desde puntos de vista del siglo $\mathrm{xx}$. Son estas interpretaciones las que siembran la confusión y llevan a adoptar posturas completamente opuestas a las que se llega utilizando los mismos tatos, manejados de una o de otra forma según la idea que previamente se tenga sobre la importancia y trascendencia, para los tiempos actuales, de lo ocurrido en Caspe, según puede ver, por citar dos ejemplos, quien lea las obras de Menéndez Pidal y de Soldevila, a ninguno de los cuales puede acusarse de ignorar lo ocurrido en Caspe.

Reprocha Soldevila a don Ramón que da una interpretación parcial porque se «esfuerza en presentar, de manera favorable, tanto si es así como si no, los hechos y figuras de la historia hispánica y, muy especialmente, aquellos que han sido objeto de críticas y censuras más o menos acerbas", y ataca don Ramón a los historiadores catalanes que, en el siglo xx, han visto en Caspe el comienzo del declive político de Cataluña, o, lo que es lo mismo, la pérdida de su independencia nacional, tema que subyace en todas las interpretaciones del Compromis, más actual hoy que en el momento en que se produjo.

Castelianistas y catalanistas parten de ideas preconcebidas sobre las ventajas e inconvenientes de la integración en España y de la independencia catalana, que les obligan a llegar necesariamente a la conclusión de que los acuerdos de Caspe fueron beneficiosos o perjudiciales. Unos y otros analizan el Compromiso desde el punto de vista de un hombre del 
siglo xx: los catalanistas, nostálgicos de la época en que Cataluña era independiente y deseosos de que el país recupere su independencia e importancia política, hacen responsables del declive nacional catalán a los compromisarios y a cuanto rodeó las decisiones de Caspe. Los castellanistas, en cambio, consideran que lo mejor que ha podido suceder a Cataluña es la integración en España y ven en Caspe el inicio de la fusión por lo que se consideran legitimados para apoyar la actuación de cuantos posibilitaron el nombramiento de Fernando de Antequera.

Si a esto unimos el apasionamiento de que unos y otros hacen gala, podremos fácilmente saber por qué después de tantas obras dedicadas a estudiar la sucesión de Martín el Humano nos encontramos ahora tan lejos de la verdad histórica como hace cien años. Tiene razón Soldevila cuando afirma que «lo que para don Ramón constituye un argumento favorable a la sucesión de Caspe y a sus consecuencias, constituye para mí un argumento sustancialmente adverso"; lo mismo podría haber dicho don Ramón refiriéndose a Soldevila, y ambos olvidan que en Caspe fue elegido rey de Aragón, Cataluña y Valencia un castellano pero que en ningún momento se planteó la posibilidad de unir las Coronas de Castilla y de Aragón, prevista en cambio, aunque como posibilidad remota, en el testamento de Jaime el Conquistador, y por los catalanes que eligieron rey, durante la guerra civil de la segunda mitad del siglo XV, a Enrique IV de Castilla.

No hay duda de que la elección de Fernando estrechó los lazos entre Castilla y Aragón, y en el estado actual de nuestros conocimientos resulta imposible saber si esta aproximación benefició o perjudicó a unos u otros - hay constancia de numerosas quejas de los castellanos, obligados a facilitar trigo a Cataluña, o por el gasto de su dinero en tierras ajenas- pero es seguro que la entronización de la dinastía castellana no puso fin a las guerras tradicionales entre ambos reinos ni al apoyo que, también tradicionalmente, cada uno de los reyes prestaba a quienes se oponían a su rival, y el hecho de que Fernando de Aragón y Juan II de Castilla descendieran de Enrique de Trastámara no significó una mayor colaboración entre los reinos, aunque es lógico suponer que entre los consejeros de Fernando y, más tarde, de sus hijos Alfonso y Juan, figuraran castellanos cuya influencia desconocemos.

Atribuir a Caspe, a la dinastía castellana, la guerra civil es ignorar los enfrentamientos entre los catalanes, entre la Busca y la Biga, entre los payeses y sus señores, entre los dirigentes del Principado, representados en las Cortes y en la Diputación General del Reino, y el monarca, oposición que se remonta al menos a los años finales del siglo XIII, a la ocupa- 
ción de Sicilia en $1282^{13}$, y se equivocan igualmente quienes defienden que el matrimonio de Isabel y Fernando tenía como objetivo la unidad de España o que se vio facilitado por la pertenencia de ambos a la misma familia. No son los afanes unitarios los que llevan a la unión de las Coronas sino la coincidencia de intereses: al mismo tiempo que Fernando proyecta su matrimonio con Isabel se ofrece como marido de Beatriz Pacheco, hija del máximo defensor de los derechos en Castilla de Juana la Beltraneja, e Isabel duda entre el matrimonio aragonés y la unión con un príncipe francés, y si al final se realiza el matrimonio se debe a que ni el rey de Aragón puede permitirse abrir un nuevo frente en Castilla ni Isabel está en condiciones de soportar la unión con el rey de Aragón de los nobles que se le oponen. La unión personal no equivale a la unión de las coronas, y a la muerte de Isabel Fernando será expulsado de Castilla donde sólo se le reconoce el título de regente, y si el matrimonio de Fernando con Germana de Foix hubiera tenido descendencia, ésta y no Juana la Loca o su hijo Carlos habrían heredado la Corona de Aragón, aunque esta última afirmación quizá no sea exacta: la unidad no es el resultado de alianzas dinásticas sino de la voluntad e intereses de quienes dirigen los reinos $\mathrm{y}$, hoy por hoy, estamos demasiado mal informados sobre la época de los Reyes Católicos para poder aventurar una hipótesis de lo que habría sucedido en el caso de que Fernando hubiera tenido hijos en su segundo matrimonio.

Sí es posible, en cambio, afirmar que el Compromiso de Caspe no significó la incorporación o integración de Cataluña en España, aunque sea punto obligado de referencia cada vez que se plantean problemas entre Cataluña y el poder, más o menos y con mayor o menor razón, identificado con Castilla. Caspe es un arma arrojadiza en épocas de crisis en Cataluña, y a reforzar su carácter de tal contribuyen los historiadores castellanistas empeñados en valorar en vez de explicar lo ocurrido en Caspe, y en valorarlo, igual que ios catalanistas, a partir de las pretendidas o reales consecuencias, sin un estudio detallado de las causas, que exigiría un conocimiento profundo del campo jurídico y también de la situación e intereses económicos, sociales y religiosos de los dirigentes catalanes y mallorquines, aragoneses, valencianos y castellanos de comienzos del siglo $\mathrm{XV}$.

13 V. mi artículo "Privilegios y cartas de libertad en la Corona de Aragón (1283-1289)", Economía y sociedad, I, pp. 185-236. 